\title{
Association between Apgar scores of 7 to 9 and neonatal mortality and morbidity: population based cohort study of term infants in Sweden
}

\author{
Neda Razaz, ${ }^{1}$ Sven Cnattingius, ${ }^{1}$ KS Joseph ${ }^{2}$
}

\section{${ }^{1}$ Division of Clinical}

Epidemiology, Department of

Medicine Solna, Karolinska

Institutet, Stockholm, Sweden

${ }^{2}$ Department of Obstetrics

\& Gynaecology, School of

Population and Public Health,

University of British Columbia

and the Children's and Women's

Hospital of British Columbia,

Vancouver, BC, Canada

Correspondence to: N Razaz

neda.razaz@gmail.com

(ORCID 0000-0002-1273-0110)

Additional material is published online only. To view please visit

the journal online.

Cite this as: BMJ 2019;365:11656 http://dx.doi.org/10.1136/bmj.l1656

Accepted: 20 March 2019

\section{ABSTRACT}

OBJECTIVE

To investigate associations between Apgar scores of 7,8 , and 9 (versus 10) at 1,5 , and 10 minutes, and neonatal mortality and morbidity.

\section{DESIGN}

Population based cohort study.

SETTING

Sweden.

\section{PARTICIPANTS}

1551436 non-malformed live singleton infants, born at term ( $\geq 37$ weeks' gestation) between 1999 and 2016, with Apgar scores of $\geq 7$ at 1,5 , and 10 minutes.

\section{EXPOSURES}

Infants with Apgar scores of 7, 8, and 9 at 1, 5, and 10 minutes were compared with those with an Apgar score of 10 at 1,5 , and 10 minutes, respectively.

\section{MAIN OUTCOME MEASURES}

Neonatal mortality and morbidity, including neonatal infections, asphyxia related complications, respiratory distress, and neonatal hypoglycaemia. Adjusted odds ratios (aOR), adjusted rate differences (aRD), and 95\% confidence intervals were estimated.

\section{RESULTS}

Compared with infants with an Apgar score of 10 , aORs for neonatal mortality, neonatal infections, asphyxia related complications, respiratory distress, and neonatal hypoglycaemia were higher among infants with lower Apgar scores, especially at 5 and 10 minutes. For example, the aORs for respiratory distress for an Apgar score of 9 versus 10 were 2.0 (95\% confidence interval 1.9 to 2.1 ) at 1 minute, 5.2 (5.1 to 5.4 ) at 5 minutes, and 12.4 (12.0 to 12.9) at 10 minutes. Compared with an Apgar score of 10

\section{WHAT IS ALREADY KNOWN ON THIS TOPIC}

An Apgar score of less than 7 has implications for neonatal mortality, morbidity, and long term neurodevelopmental outcomes

No previous study has investigated whether Apgar scores of 7, 8, and 9 (compared with 10) are associated with neonatal mortality and morbidity

\section{WHAT THIS STUDY ADDS}

In term, non-malformed infants, the risks of neonatal mortality and morbidity were higher among those with lower Apgar score values within the normal range (7 to 9) at 1, 5, and 10 minutes

Even a small change in Apgar score from 5 minutes to 10 minutes was associated with higher risks of neonatal morbidity

The optimal Apgar score is 10 at each time point, and all newborns should be assigned an Apgar score at 10 minutes, regardless of their score at 1 minute and 5 minutes

at 10 minutes, the aRD for respiratory distress was 9.5\% (95\% confidence interval $9.2 \%$ to $9.9 \%$ ) for an Apgar score of 9 at 10 minutes, and $41.9 \%$ (37.7\% to $46.4 \%$ ) for an Apgar score of 7 at 10 minutes. A reduction in Apgar score from 10 at 5 minutes to 9 at 10 minutes was also associated with higher odds of neonatal morbidity, compared with a stable Apgar score of 10 at 5 and 10 minutes.

\section{CONCLUSIONS}

In term non-malformed infants with Apgar scores within the normal range (7 to 10), risks of neonatal mortality and morbidity are higher among infants with lower Apgar score values, and also among those experiencing a reduction in score from 5 minutes to 10 minutes (compared with infants with stable Apgar scores of 10).

\section{Introduction}

The most routinely used measure of health status of newborns is the Apgar score, typically quantified at 1 , 5 , and 10 minutes after birth. ${ }^{1}$ Our recent population based studies have shown that non-malformed term infants born with lower Apgar scores within the normal range ( 7 to 9) at 1, 5, or 10 minutes are at higher risk of adverse long term outcomes, such as epilepsy, cerebral palsy, having additional needs, and adverse child developmental health (compared with non-malformed term infants with an Apgar score of 10)..$^{2-4}$ Both the timing and the score are important: compared with an Apgar score of 10 at 5 and 10 minutes, an Apgar score of 9 at 5 minutes and an Apgar score of 9 at 10 minutes are both associated with an increased risk of cerebral palsy, with an Apgar score of 9 at 10 minutes conferring higher risk of cerebral palsy than an Apgar score of 9 at 5 minutes. ${ }^{3}$

The findings of differential risks associated with Apgar scores within the normal range are unexpected as it is commonly assumed that Apgar scores of 9 versus 10 are assigned arbitrarily. This belief is supported by international comparisons of Apgar scores, which show that the frequency of Apgar scores of 10 at 5 minutes vary from $8.8 \%$ in some countries to $92.7 \%$ in others. ${ }^{5}$ It is widely recognised that a low Apgar score, commonly defined as a score less than 7 , is associated with increased risks of neonatal mortality, ${ }^{67}$ morbidity, ${ }^{8-10}$ and long term outcomes ${ }^{11-16}$; however, no previous study has investigated whether Apgar scores of 7, 8, and 9 are similarly associated with higher risks of neonatal mortality and morbidity. Quantifying associations between Apgar scores in the normal range and neonatal morbidity, such as neonatal infections, neonatal respiratory distress, and hypoxic-ischaemic 
encephalopathy is important because such conditions are known risk factors for later neurodevelopmental adversity in children. In this population based study of more than 1.5 million infants born in Sweden, we evaluated associations between Apgar scores of 7, 8, and 9 (versus 10) at 1, 5, or 10 minutes and risks of neonatal mortality and morbidity.

\section{Methods}

We based our study on singleton live births in Sweden between 1999 and 2016, with data obtained from the Medical Birth Register. ${ }^{17}$ This database contains information on antenatal, obstetrical, and neonatal care that is prospectively recorded on standardised forms for more than $98 \%$ of births in Sweden. The most recent extensive validation of the Medical Birth Register showed that coverage and validity of most variables were high. ${ }^{18}$ Using the person-unique national registration numbers of mothers and infants, we linked data from the Birth Register to several national registries. The nationwide National Patient Register $^{19} 20$ includes diagnostic codes on hospital in-patient care since 1987 and hospital out-patient care from 2001. We coded diagnoses in the patient and birth registers using the Swedish versions of the International Classification of Diseases, 10th Revision (ICD-10) from 1997 onwards. We obtained information on neonatal deaths from the National Cause of Death Register, which includes information on all deaths in Sweden since $1961 .^{21}$ Information on maternal education and country of origin was obtained from the Education Register and the Total Population Register, respectively. ${ }^{22} 23$

\section{Study population}

We analysed data for 18 years (1999-2016), during which 1834641 singleton live births were recorded in the Birth Register. We excluded preterm infants ( $\leq 36$ completed weeks' gestation, $n=94545$ ), infants with major congenital malformations ( $n=60762)$, and records with missing data on maternal or infant identification numbers ( $\mathrm{n}=25658)$, leaving 1653676 term ( $\geq 37$ completed weeks' gestation) singleton, nonmalformed infants. Complete information on Apgar scores at 1 and 5 minutes was available for 1645396 infants (99\%), of whom 1620473 (98.5\%) also had information on Apgar scores at 10 minutes. We restricted our study population to infants with Apgar scores of 7 to 10 at 1,5 , and 10 minutes $(n=1551436)$.

We obtained data on neonatal mortality and morbidity from nationwide Swedish registries: the Medical Birth Register and the Swedish patient and cause of death registers. Neonatal mortality was defined as infant deaths within the first 0-27 days after birth. Neonatal morbidity, assessed in the first 0-27 days after birth, included neonatal infections, asphyxia related neonatal complications (hypoxic-ischaemic encephalopathy and related conditions, and neonatal convulsions/seizures), neonatal hypoglycaemia, and respiratory distress (see supplementary table A for specific ICD-10 codes).
In Sweden, all women are offered an ultrasound scan at 18 weeks' gestation or earlier for dating and screening for congenital abnormalities. In our study, we estimated gestational age (in completed weeks) using the following hierarchy: date of early second trimester ultrasonography (87.7\%), date of last menstrual period (7.4\%), or a postnatal assessment $(4.9 \%)$.

Among maternal characteristics, we retrieved information on age at delivery, country of origin, highest attained level of education, cohabitation with a partner, parity, height, body mass index (BMI, $\mathrm{kg} / \mathrm{m}^{2}$ ), and smoking during pregnancy. Maternal age at delivery was calculated as date of delivery minus the mother's birth date, and parity was defined as the number of births to each mother (including the index birth). BMI was calculated using weight measured at registration to antenatal care (wearing light indoor clothing) and self reported height. BMI was categorised according to the World Health Organization groups as underweight (BMI <18.5), normal weight (18.5 to $<25)$, overweight ( 25 to $<30$ ), obesity grade 1 (30 to $<35$ ), obesity grade 2 ( 35 to $<40)$, or obesity grade $3(\geq 40.0) .{ }^{24}$ We obtained information on cohabitation with a partner during the first antenatal visit. Mothers who reported daily smoking at the first antenatal visit and/or at 30 to 32 weeks' gestation were classified as smokers, whereas mothers who stated that they were non-smokers were classified as such. Information on induction of labour and mode of delivery was noted on the obstetric record at onset of labour and after delivery, respectively.

\section{Statistical analyses}

The frequency of each Apgar score value was calculated within categories of maternal and infant characteristics. Logistic regression was used to examine associations between Apgar scores of 7, 8, or 9 (versus 10) at 1, 5, or 10 minutes and neonatal mortality and each neonatal morbidity. Results were expressed as odds ratios with $95 \%$ confidence intervals. In the multivariable analyses, estimates were adjusted for maternal factors (age at childbirth, parity, country of birth, education, smoking, cohabitation with a partner, height and early pregnancy BMI) and birth characteristics of the infant (sex, gestational age in weeks, and year of birth). Lastly, the magnitude of absolute effects was quantified by calculating adjusted rate differences. The adjusted rate difference represents the number of excess cases of neonatal mortality and morbidity per 100 births among infants receiving an Apgar score of 7, 8 , or 9 at 1,5 , and 10 minutes compared with infants receiving an Apgar score of 10 . Two sided P values of less than 0.05 were considered to indicate statistical significance.

\section{Supplementary analyses}

Pregnancy and delivery complications are associated with increased risks of a low Apgar score (0 to 6) and neonatal morbidity. ${ }^{91025}$ We therefore also quantified the association between risk factors, such as gestational diabetes, pre-eclampsia, chorioamnionitis, placental abruption, premature rupture of membranes, 
induction of labour, mode of delivery, and meconium aspiration (see supplementary table A for specific ICD10 codes) and Apgar scores of 7, 8, and 9 (versus 10) at 1 , 5, or 10 minutes. Logistic regression with the Apgar score of interest (eg, 5 minute Apgar score of 9 versus 10) as the dependent variable was used to obtain odds ratios and 95\% confidence intervals for each risk factor.

\section{Patient and public involvement}

This study was based on analysis of information from linked databases and no patients were involved in designing the research question or the outcome measures, nor were they involved in developing plans for implementation of the study. No patients were asked to advise on interpretation or writing up of results.

\section{Results}

Only $11 \%(163800 / 1551436)$ of infants had an Apgar score of 10 at 1 minute, whereas $89 \%$ (1373 314/1 551436) and 97\% (1501605/1551436) had a score of 10 at 5 and 10 minutes, respectively. Apgar scores of 10 at 5 minutes were less common in offspring of mothers who were primiparous, born in Sweden, shorter $(<159 \mathrm{~cm})$, or very obese $(\mathrm{BMI} \geq 35$ $\mathrm{kg} / \mathrm{m}^{2}$ ), and less common in those who delivered at 37 weeks' and $\geq 42$ weeks' gestation. The frequency of an Apgar score of 10 at 5 minutes was also lower in boys compared with girls (table 1 ).

\section{Neonatal mortality and morbidity}

Apgar scores of 7, 8, and 9 at 1, 5, and 10 minutes were strongly associated with neonatal mortality and morbidity, compared with an Apgar score of 10 at 1,5 , and 10 minutes (fig 1, supplementary table B). Compared with an Apgar score of 10 at 10 minutes, adjusted odds ratios for neonatal mortality increased from 4.8 for an Apgar score of 9 at 10 minutes to 29.8 for an Apgar score of 7 at 10 minutes (fig 1; supplementary table B). Furthermore, adjusted odds ratios between lower Apgar score values and neonatal mortality and each neonatal morbidity were higher with increasing time after birth. For example, compared with an Apgar score of 10 at 1 minute, an Apgar score of 9 at 1 minute was associated with 1.5-fold higher adjusted odds of neonatal infections, whereas the association was larger at 5 and 10 minutes (adjusted odds ratios 2.1 and 3.3, respectively). Asphyxia related complications, neonatal hypoglycaemia, and respiratory distress were also strongly associated with Apgar scores of 7, 8, and 9, and adjusted odds ratios increased with time since birth. The adjusted rate difference for respiratory distress was 9.5\% (95\% confidence interval $9.2 \%$ to $9.9 \%$ ) for an Apgar score of 9 at 10 minutes and increased to $41.9 \%$ (37.7\% to 46.4\%) for an Apgar score of 7 at 10 minutes, compared with an Apgar score of 10 at 10 minutes (table 2). Lastly, the association between Apgar score and neonatal morbidity remained strong regardless of mode of delivery, and the highest odds ratios were observed for infants born following a non-instrumental vaginal delivery (supplementary table $\mathrm{C}$ ).

\section{Combinations}

Table 3 shows adjusted odds ratios for neonatal mortality and morbidity in relation to changes in Apgar score values from 5 to 10 minutes. A reduction of Apgar score from 10 at 5 minutes to 9 at 10 minutes was associated with higher adjusted odds ratios for neonatal infections, neonatal hypoglycaemia, and respiratory distress (compared with an Apgar score of 10 at both 5 and 10 minutes). For instance, compared with Apgar scores of 10 at both time points, a reduction in Apgar score from 10 at 5 minutes to 9 at 10 minutes was associated with a 4.1-fold higher odds of neonatal infections. Compared with Apgar scores of 10 at both time points, infants whose Apgar scores increased from 9 at 5 minutes to 10 at 10 minutes also had higher relative odds for all outcomes including neonatal mortality. For example, compared with Apgar scores of 10 at both time points, an improvement from an Apgar score of 9 at 5 minutes to 10 at 10 minutes was associated with a 1.8 -fold higher odds of neonatal infections (adjusted odds ratio 1.8, 95\% confidence interval 1.7 to 1.9 ).

\section{Supplementary analyses}

Pregnancy and delivery factors, including gestational diabetes, pre-eclampsia, chorioamnionitis, placental abruption, induced onset of labour, vaginal instrumental or caesarean delivery, and meconium aspiration were associated with Apgar scores of 7, 8, and 9 (versus 10) at 5 and 10 minutes (see supplementary table D). The strength of association differed markedly, and the highest relative odds were obtained for preeclampsia, chorioamnionitis, placental abruption, vaginal instrumental delivery, emergency caesarean delivery, and meconium aspiration. Premature rupture of the membranes was not associated with increased odds for Apgar scores of 7, 8, or 9 at 5 or 10 minutes. Pregnancy and delivery factors were not or were only modestly associated with Apgar scores of 7, 8, or 9 versus 10 at 1 minute, except for vaginal instrumental delivery and meconium aspiration, which were associated with markedly higher odds of an Apgar score of 7,8 , or 9 at 1 minute (eg, the adjusted odds ratio for an Apgar score of 9 versus 10 at 1 minute for meconium aspiration was 3.7 (95\% confidence interval 1.9 to 7.2$)$ ).

\section{Discussion}

In this nationwide Swedish cohort study, we found that a lower Apgar score within the normal range at 1,5 , and 10 minutes is strongly associated with increased risks of neonatal mortality and morbidity. Furthermore, we found progressively higher relative odds of neonatal mortality, infections, asphyxia related complications, neonatal hypoglycaemia, and respiratory distress with lower Apgar scores (7 to 9) at 1,5 , and 10 minutes. The relative odds of neonatal mortality and morbidity associated with lower Apgar scores (in the normal range) increased with increasing time from birth. A small change in Apgar score from 5 minutes to 10 minutes (eg, from 


\begin{tabular}{|c|c|c|c|c|c|}
\hline \multirow[b]{2}{*}{ Characteristics } & \multirow{2}{*}{$\begin{array}{l}\text { Total No } \\
(n=1551436)\end{array}$} & \multicolumn{4}{|c|}{ Apgar score at 5 mins } \\
\hline & & $7(n=3335)$ & $8(n=20913)$ & $9(n=153874)$ & $10(n=1373314)$ \\
\hline \multicolumn{6}{|l|}{ Maternal age (years): } \\
\hline$\leq 19$ & 23127 & $50(0.2)$ & $282(1.2)$ & $2139(9.2)$ & $20656(89.3)$ \\
\hline $20-24$ & 198475 & $438(0.2)$ & $2714(1.4)$ & $18913(9.5)$ & $176410(88.9)$ \\
\hline $25-29$ & 475860 & $1019(0.2)$ & $6516(1.4)$ & $47785(10.0)$ & $420540(88.4)$ \\
\hline $30-34$ & 537904 & $1135(0.2)$ & $7034(1.3)$ & $53528(10.0)$ & $476207(88.5)$ \\
\hline$\geq 35$ & 316070 & $693(0.2)$ & $4367(1.4)$ & $31509(10.0)$ & $279501(88.4)$ \\
\hline \multicolumn{6}{|l|}{ Parity: } \\
\hline 1 & 669292 & $1951(0.3)$ & $12270(1.8)$ & $70176(10.5)$ & $584895(87.4)$ \\
\hline 2 & 579715 & $907(0.2)$ & $5717(1.0)$ & $54192(9.3)$ & $518899(89.5)$ \\
\hline 3 & 212387 & $316(0.1)$ & $2081(1.0)$ & $20614(9.7)$ & $189376(89.2)$ \\
\hline$\geq 4$ & 90042 & $161(0.2)$ & $845(0.9)$ & $8892(9.9)$ & $80144(89.0)$ \\
\hline \multicolumn{6}{|l|}{ Country of birth: } \\
\hline Sweden & 1208381 & $2654(0.2)$ & $17105(1.4)$ & $127091(10.5)$ & $1061531(87.8)$ \\
\hline Other Nordic countries & 25012 & $52(0.2)$ & $344(1.4)$ & $2546(10.2)$ & $22070(88.2)$ \\
\hline Non-Nordic countries & 316237 & $619(0.2)$ & $3452(1.1)$ & $24109(7.6)$ & $288057(91.1)$ \\
\hline Missing & 1806 & $10(0.6)$ & $12(0.7)$ & $128(7.1)$ & $1656(91.7)$ \\
\hline \multicolumn{6}{|l|}{ Education (years): } \\
\hline$\leq 9$ & 137826 & $302(0.2)$ & $1699(1.2)$ & $12315(8.9)$ & $123510(89.6)$ \\
\hline $10-11$ & 186936 & $400(0.2)$ & $2415(1.3)$ & $19082(10.2)$ & $165039(88.3)$ \\
\hline 12 & 400534 & $840(0.2)$ & $5556(1.4)$ & $40138(10.0)$ & $354000(88.4)$ \\
\hline $13-14$ & 212304 & $454(0.2)$ & $2897(1.4)$ & $20929(9.9)$ & $188024(88.6)$ \\
\hline$\geq 15$ & 601624 & $1299(0.2)$ & $8183(1.4)$ & $60483(10.1)$ & $531659(88.4)$ \\
\hline Missing & 12212 & $40(0.3)$ & $163(1.3)$ & $927(7.6)$ & $11082(90.7)$ \\
\hline \multicolumn{6}{|l|}{ Smoking during pregnancy: } \\
\hline No & 1370576 & $2947(0.2)$ & $18678(1.4)$ & $136846(10.0)$ & $1212105(88.4)$ \\
\hline Yes & 120616 & $264(0.2)$ & $1395(1.2)$ & $11470(9.5)$ & $107487(89.1)$ \\
\hline Missing & 60244 & $124(0.2)$ & $840(1.4)$ & $5558(9.2)$ & $53722(89.2)$ \\
\hline \multicolumn{6}{|c|}{ Mother cohabits with partner: } \\
\hline Yes & 1394644 & $2978(0.2)$ & $18683(1.3)$ & $139471(10.0)$ & $1233512(88.4)$ \\
\hline No & 85266 & $214(0.3)$ & $1262(1.5)$ & $8050(9.4)$ & $75740(88.8)$ \\
\hline Missing & 71526 & $143(0.2)$ & $968(1.4)$ & $6353(8.9)$ & $64062(89.6)$ \\
\hline \multicolumn{6}{|l|}{ Maternal height $(\mathrm{cm})$ : } \\
\hline$\leq 159$ & 191299 & $492(0.3)$ & $2938(1.5)$ & $19241(10.1)$ & $168628(88.1)$ \\
\hline $160-164$ & 371064 & $883(0.2)$ & $5335(1.4)$ & $38321(10.3)$ & $326525(88.0)$ \\
\hline $165-169$ & 430854 & $900(0.2)$ & $5846(1.4)$ & $43272(10.0)$ & $380836(88.4)$ \\
\hline$\geq 170$ & 480148 & $903(0.2)$ & $5764(1.2)$ & $45720(9.5)$ & $427761(89.1)$ \\
\hline Missing & 78071 & $157(0.2)$ & $1030(1.3)$ & $7320(9.4)$ & $69564(89.1)$ \\
\hline \multicolumn{6}{|l|}{ Maternal BMI: } \\
\hline$<18.5$ & 33673 & $42(0.1)$ & $350(1.0)$ & $2608(7.7)$ & $30673(91.1)$ \\
\hline $18.5-24.9$ & 857501 & $1674(0.2)$ & $10666(1.2)$ & $81478(9.5)$ & $763683(89.1)$ \\
\hline $25-29.9$ & 356678 & $880(0.2)$ & $5123(1.4)$ & $37291(10.5)$ & $313384(87.9)$ \\
\hline $30-34.9$ & 116886 & $290(0.2)$ & $1925(1.6)$ & $12973(11.1)$ & $101698(87.0)$ \\
\hline$\geq 35$ & 47352 & $150(0.3)$ & 901 (1.9) & $5605(11.8)$ & $40696(85.9)$ \\
\hline Missing & 139346 & $299(0.2)$ & $1948(1.4)$ & $13919(10.0)$ & $123180(88.4)$ \\
\hline \multicolumn{6}{|l|}{ Infant sex: } \\
\hline Boy & 784782 & $1785(0.2)$ & $11461(1.5)$ & $84045(10.7)$ & $687491(87.6)$ \\
\hline Girl & 766654 & $1550(0.2)$ & $9452(1.2)$ & $69829(9.1)$ & $685823(89.5)$ \\
\hline \multicolumn{6}{|l|}{ Gestational age (weeks): } \\
\hline 37 & 33932 & $136(0.4)$ & $709(2.1)$ & $3798(11.2)$ & $29289(86.3)$ \\
\hline 38 & 130721 & $372(0.3)$ & $1996(1.5)$ & $12862(9.8)$ & $115491(88.3)$ \\
\hline 39 & 279225 & $528(0.2)$ & $3424(1.2)$ & $25449(9.1)$ & $249824(89.5)$ \\
\hline 40 & 410458 & $766(0.2)$ & 4669 (1.1) & $38540(9.4)$ & $366483(89.3)$ \\
\hline 41 & 387388 & $747(0.2)$ & $5072(1.3)$ & $38661(10.0)$ & $342908(88.5)$ \\
\hline$\geq 42$ & 309712 & $786(0.3)$ & $5043(1.6)$ & 34564 (11.2) & $269319(87.0)$ \\
\hline \multicolumn{6}{|l|}{ Year of delivery: } \\
\hline 1999-2004 & 447250 & $794(0.2)$ & $6554(1.5)$ & $51738(11.6)$ & $388164(86.8)$ \\
\hline $2005-08$ & 347334 & $617(0.2)$ & $4702(1.4)$ & 34959 (10.1) & $307056(88.4)$ \\
\hline 2009-12 & 373705 & $814(0.2)$ & $4640(1.2)$ & $33154(8.9)$ & $335097(89.7)$ \\
\hline 2013-16 & 383147 & $1110(0.3)$ & $5017(1.3)$ & $34023(8.9)$ & $342997(89.5)$ \\
\hline
\end{tabular}

10 to 9) was also associated with an increased risk of neonatal morbidity. Pregnancy and delivery related factors, such as pre-eclampsia, chorioamnionitis, placental abruption, induced onset of labour, vaginal instrumental delivery, and meconium aspiration were associated with Apgar scores of 7 to 9 (versus 10), suggesting that low Apgar scores in the normal range represent early prognostic indicators highlighting the effects of pregnancy and delivery complications on neonatal morbidity. 


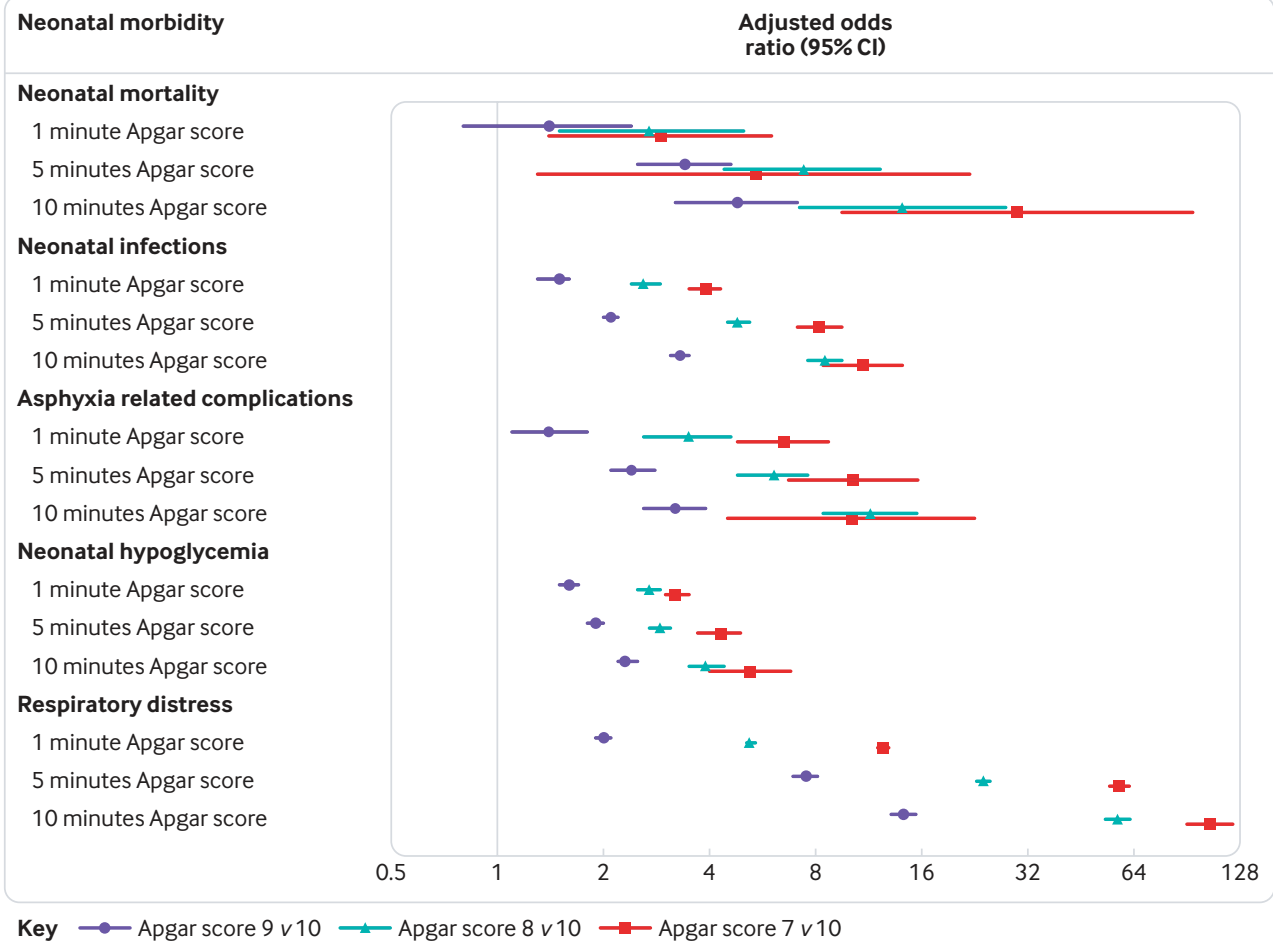

Fig 1 Associations between Apgar scores of 7, 8, and 9 at 1, 5, and 10 minutes and neonatal mortality and morbidity among term singleton live births in Sweden, 1999-2016

\begin{tabular}{|c|c|c|c|c|c|c|}
\hline \multirow[b]{2}{*}{ Variables } & \multicolumn{2}{|c|}{1 min Apgar score } & \multicolumn{2}{|c|}{5 min Apgar score } & \multicolumn{2}{|c|}{10 min Apgar score } \\
\hline & No (\%) & Adjusted RD $(95 \% \mathrm{Cl})^{*}$ & No (\%) & $\begin{array}{l}\text { Adjusted rate difference } \\
(95 \% \mathrm{Cl})^{\star}\end{array}$ & No (\%) & $\begin{array}{l}\text { Adjusted rate difference } \\
(95 \% \mathrm{Cl})^{\star}\end{array}$ \\
\hline \multicolumn{7}{|c|}{ Neonatal mortality } \\
\hline \multicolumn{7}{|c|}{ Apgar scores: } \\
\hline 7 & $16(0.03)$ & $0.02(0.004$ to 0.1$)$ & $4(0.1)$ & $0.04(0.003$ to 0.2$)$ & $5(0.6)$ & $0.6(0.2$ to 1.9$)$ \\
\hline 8 & $42(0.03)$ & $0.02(0.005$ to 0.04$)$ & $22(0.1)$ & $0.1(0.03$ to 0.1$)$ & $11(0.2)$ & $0.3(0.1$ to 0.5$)$ \\
\hline 9 & $207(0.02)$ & $0.004(-0.002$ to 0.01$)$ & $67(0.04)$ & $0.02(0.02$ to 0.04$)$ & $35(0.1)$ & 0.1 (0.04 to 0.1$)$ \\
\hline 10 & $17(0.01)$ & Reference & $189(0.01)$ & Reference & $231(0.02)$ & Reference \\
\hline \multicolumn{7}{|c|}{ Neonatal infections } \\
\hline \multicolumn{7}{|c|}{ Apgar scores: } \\
\hline 7 & $1252(2.4)$ & $1.5(1.3$ to 1.7$)$ & $210(6.3)$ & $5.5(4.7$ to 6.5$)$ & $71(8.7)$ & $8.3(6.2$ to 11$)$ \\
\hline 8 & $2051(1.7)$ & 0.8 (0.7 to 1$)$ & $856(4.1)$ & 2.9 (2.7 to 3.2$)$ & $375(7.4)$ & $6.3(5.5$ to 7.1$)$ \\
\hline 9 & $9834(0.8)$ & $0.3(0.2$ to 0.3$)$ & $2595(1.7)$ & 0.8 (0.8 to 0.9$)$ & $1288(2.9)$ & $1.9(1.8$ to 2.1$)$ \\
\hline 10 & $823(0.5)$ & Reference & $10299(0.7)$ & Reference & $12226(0.8)$ & Reference \\
\hline \multicolumn{7}{|c|}{ Asphyxia related complications } \\
\hline \multicolumn{7}{|c|}{ Apgar scores: } \\
\hline 7 & $178(0.3)$ & $0.2(0.2$ to 0.3$)$ & $25(0.7)$ & $0.6(0.4$ to 1.0$)$ & $6(0.7)$ & $0.7(0.3$ to 1.7$)$ \\
\hline 8 & $218(0.2)$ & $0.1(0.1$ to 0.1$)$ & $105(0.5)$ & $0.4(0.3$ to 0.5$)$ & $54(1.1)$ & $0.8(0.6$ to 1.2$)$ \\
\hline 9 & $834(0.1)$ & $0.02(0.01$ to 0.03$)$ & $259(0.2)$ & $0.1(0.1$ to 0.1$)$ & $116(0.3)$ & $0.2(0.1$ to 0.2$)$ \\
\hline 10 & $69(0.04)$ & Reference & $910(0.1)$ & Reference & $1123(0.1)$ & Reference \\
\hline \multicolumn{7}{|c|}{ Neonatal hypoglycaemia } \\
\hline \multicolumn{7}{|c|}{ Apgar scores: } \\
\hline 7 & $1799(3.5)$ & $2.4(2.2$ to 2.8$)$ & $228(6.8)$ & $5.4(4.4$ to 6.4$)$ & $74(9.1)$ & $7.4(5.3$ to 10.2$)$ \\
\hline 8 & $3539(2.9)$ & 1.9 (1.7 to 2.1$)$ & $1038(5.0)$ & $3.1(2.8$ to 3.4$)$ & $354(7.0)$ & $5.1(4.4$ to 6.0$)$ \\
\hline 9 & $18815(1.6)$ & 0.7 (0.6 to 0.8$)$ & $4496(2.9)$ & $1.5(1.3$ to 1.6$)$ & $1765(4.0)$ & $2.3(2.1$ to 2.6$)$ \\
\hline 10 & $1460(0.9)$ & Reference & $19851(1.4)$ & Reference & $23420(1.6)$ & Reference \\
\hline \multicolumn{7}{|c|}{ Respiratory distress } \\
\hline \multicolumn{7}{|c|}{ Apgar scores: } \\
\hline 7 & $3736(7.3)$ & $6.0(5.6$ to 6.6$)$ & $1127(33.8)$ & $27.9(26.1$ to 29.9$)$ & $431(52.8)$ & 41.9 (37.7 to 46.4$)$ \\
\hline 8 & $4920(4.0)$ & $3.1(2.9$ to 3.4$)$ & $3628(16.3)$ & 14.6 (14 to 15.2$)$ & $1952(38.5)$ & 31.9 (30.2 to 33.5) \\
\hline 9 & $12732(1.0)$ & 0.5 (0.4 to 0.6$)$ & $6446(4.2)$ & 3.2 (3 to 3.3 ) & $5101(11.6)$ & 9.5 (9.2 to 9.9$)$ \\
\hline 10 & $896(0.5)$ & Reference & $11083(0.8)$ & Reference & $14800(1.0)$ & Reference \\
\hline
\end{tabular}




\begin{tabular}{|c|c|c|c|c|}
\hline \multirow[b]{2}{*}{ Morbidity } & \multicolumn{2}{|c|}{ Apgar score } & \multirow[b]{2}{*}{ No (\%) } & \multirow{2}{*}{$\begin{array}{l}\text { Adjusted odds ratio } \\
(95 \% \mathrm{Cl})^{\star}\end{array}$} \\
\hline & $5 \mathrm{~min}$ & $10 \mathrm{~min}$ & & \\
\hline \multirow{5}{*}{ Neonatal mortality } & 10 & 10 & $188(0.01)$ & Reference \\
\hline & 10 & 9 & $1(0.1)$ & - \\
\hline & 9 & 10 & $39(0.03)$ & $2.8(2.0$ to 4.0$)$ \\
\hline & 9 & 9 & $27(0.1)$ & $5.5(3.5$ to 8.7$)$ \\
\hline & 9 & $<9$ & $1(0.2)$ & - \\
\hline \multirow{5}{*}{ Neonatal infections } & 10 & 10 & $10266(0.7)$ & Reference \\
\hline & 10 & 9 & $27(3.7)$ & $4.1(2.7$ to 6.4$)$ \\
\hline & 9 & 10 & $1716(1.4)$ & $1.8(1.7$ to 1.9$)$ \\
\hline & 9 & 9 & $848(2.5)$ & $3.0(2.8$ to 3.3$)$ \\
\hline & 9 & $<9$ & $31(6.0)$ & $6.9(4.6$ to 10.4$)$ \\
\hline \multirow{5}{*}{ Asphyxia related complications } & 10 & 10 & $907(0.1)$ & Reference \\
\hline & 10 & 9 & $2(0.3)$ & - \\
\hline & 9 & 10 & $194(0.2)$ & $2.4(2.0$ to 2.8$)$ \\
\hline & 9 & 9 & $63(0.2)$ & $2.6(2.0$ to 3.5$)$ \\
\hline & 9 & $<9$ & $2(0.4)$ & - \\
\hline \multirow{5}{*}{ Neonatal hypoglycaemia } & 10 & 10 & $19814(1.4)$ & Reference \\
\hline & 10 & 9 & $31(4.3)$ & 2.5 (1.7 to 3.7$)$ \\
\hline & 9 & 10 & $3225(2.7)$ & $1.8(1.7$ to 1.8$)$ \\
\hline & 9 & 9 & $1239(3.6)$ & $2.3(2.2$ to 2.4$)$ \\
\hline & 9 & $<9$ & $32(6.2)$ & $3.8(2.6$ to 5.6$)$ \\
\hline \multirow{5}{*}{ Respiratory distress } & 10 & 10 & $10883(0.8)$ & Reference \\
\hline & 10 & 9 & $156(21.6)$ & $29.0(23.9$ to 35.3$)$ \\
\hline & 9 & 10 & $3138(2.6)$ & $3.3(3.2$ to 3.4$)$ \\
\hline & 9 & 9 & $3088(9.0)$ & $11.7(11.1$ to 12.2$)$ \\
\hline & 9 & $<9$ & $220(42.6)$ & 77.1 (63.8 to 93.3) \\
\hline
\end{tabular}

*Adjusted for maternal factors (age at childbirth, parity, country of birth, education, smoking, cohabitation with a partner, height and early pregnancy BMI) and birth characteristics of the infant (sex, gestational age in weeks, and year of birth). study expands on these findings by showing that even "normal" Apgar scores (7 to 9) are strongly associated with higher risks of neonatal mortality and neonatal morbidity, and neonatal morbidity is associated with risks of long term neurological disorders. ${ }^{28}$ These findings are consistent with evidence suggesting that some infants with reassuring Apgar scores (7 to 9) with acidaemia have higher rates of adverse outcomes. ${ }^{29}$ Furthermore, risks associated with a low Apgar score (in the normal range) at 10 minutes were generally higher than those associated with the same score at 1 or 5 minutes. The strong relations between Apgar scores of 7, 8, and 9 and neonatal morbidity, and the associations between pregnancy complications and lower Apgar scores in the normal range observed in our study, provide insight into previous findings of increased risks of cerebral palsy, epilepsy, autism, and adverse developmental outcomes in children with Apgar scores of 7, 8, and even 9, compared with an Apgar score of $10 .^{2330}$

In our study only $11 \%$ of infants had an Apgar score of 10 at 1 minute, which is typically attributable to a reduction in score for skin colour. This finding warrants attention as our results show that an Apgar score of 9 at 1 minute was associated with higher risk of neonatal morbidity. Although a reduction in the 5 minute Apgar score due to colour is independently associated with an increased risk of infant mortality, ${ }^{8}$ current guidelines consider Apgar scores of 7 or more at 1 and 5 minutes to be reassuring. ${ }^{31}$ Our findings of an incremental increase in the risks of neonatal mortality and morbidity among infants with Apgar scores of 7, 8, and 9 at 1, 5, and 10 minutes, along with previous results of a linear relation ${ }^{2-430}$ between decreasing Apgar scores and increasing risk of adverse neurodevelopmental outcomes, suggest that efforts should be made to reduce the rate of low Apgar scores within the normal range and to strive for an Apgar score of 10 immediately after birth.

Seizures, intracranial haemorrhage, and birth asphyxia have been shown to be associated with Apgar scores of less than 7 at 5 and 10 minutes. ${ }^{9}$ Our study is, to our knowledge, the first to show an association between a reduction in Apgar score (from 10 at 5 minutes to $\leq 9$ at 10 minutes) and increased risks of neonatal mortality and morbidity, including infections, asphyxia related conditions, and respiratory distress. A low Apgar score at 5 minutes and 10 minutes might indicate the lack of an optimal response to resuscitation and could imply an adverse long term prognosis. ${ }^{9} \mathrm{~A}$ reduction in Apgar score from 5 minutes to 10 minutes is also associated with higher risks of later developing cerebral palsy, epilepsy, or other developmental adversity. ${ }^{34}$ Although Apgar scores at 10 minutes are often not recorded in the medical charts if scores are within the normal range (7 to 10) at 5 minutes, our findings suggest that all newborns should be assigned an Apgar score at 10 minutes, regardless of their score at 1 minute and 5 minutes. This will enable at-risk neonates to be identified and monitored to minimise the risk of adverse outcomes. 


\section{Conclusions}

Our study shows that low Apgar scores within the normal range (7 to 10) are strongly associated with neonatal mortality and morbidity and that these associations are substantially stronger with increasing time after birth. Additionally, a decrease in Apgar score from 10 at 5 minutes to 9 or less at 10 minutes is associated with a higher risk of neonatal morbidity. Our findings provide strong evidence to support the proposition that the optimal Apgar score is 10 at each time point, and all newborns should be assigned an Apgar score at 10 minutes, regardless of their score at 1 minute and 5 minutes.

Contributors: NR and SC had full access to all the data in the study and take full responsibility for the integrity of the data and the accuracy of the data analysis. They are the guarantors. NR, SC, and KSJ conceived and designed the study. All authors interpreted the data and critically revised the manuscript for important intellectual content. NR drafted the manuscript and carried out the statistical analysis. SC obtained funding and provided administrative, technical, or material support.

Funding: This study was funded by the Swedish Research Council for Health, Working Life and Welfare (grant No 2017-00134), and by an unrestricted grant from Karolinska Institutet (No 2368/10221, Distinguished Professor Award to SC). NR is supported by a postdoctoral fellowship award from the Canadian Institutes of Health Research. KS) is supported by the BC Children's Hospital Research Institute. Funders were not involved in the design and conduct of the study; collection, management, analysis, or interpretation of the data and preparation, review, or approval of the manuscript.

Competing interests: All authors have completed the ICMJE uniform disclosure form at www.icmje.org/coi_disclosure.pdf and declare: no support from any organisation for the submitted work; no financial relationships with any organisations that might have an interest in the submitted work in the previous three years; no other relationships or activities that could appear to have influenced the submitted work.

Ethical approval: This study was approved by the regional ethic review board at Karolinska Institutet, Stockholm, Sweden (No 2018/1377-32)

Data sharing: No additional data available.

Transparency: The lead author (NR) affirms that the manuscript is an honest, accurate, and transparent account of the study being reported; that no important aspects of the study have been omitted; and that any discrepancies from the study as planned (and, if relevant, registered) have been explained.

This is an Open Access article distributed in accordance with the terms of the Creative Commons Attribution (CC BY 4.0) license, which permits others to distribute, remix, adapt and build upon this work, for commercial use, provided the original work is properly cited. See: http://creativecommons.org/licenses/by/4.0/.

1 Apgar V. A proposal for a new method of evaluation of the newborn infant. Curr Res Anesth Analg 1953;32:260-7. doi:10.1213/00000539-195301000-00041

2 Razaz N, Boyce WT, Brownell M, et al. Five-minute Apgar score as a marker for developmental vulnerability at 5 years of age. Arch Dis Child Fetal Neonatal Ed 2016;101:F114-20. doi:10.1136/ archdischild-2015-308458

3 Persson M, Razaz N, Tedroff K, Joseph KS, Cnattingius S. Five and 10 minute Apgar scores and risks of cerebral palsy and epilepsy: population based cohort study in Sweden. BMJ 2018;360:k207. doi:10.1136/bmj.k207

4 Razaz N, Cnattingius S, Persson M, et al. 1 and 5-minute Apgar scores and child developmental health at 5 years of age, a populationbased cohort study. BMJ Open [in press].

5 Siddiqui A, Cuttini M, Wood R, et al, Euro-Peristat Scientific Committee. Can the Apgar score be used for international comparisons of newborn health?Paediatr Perinat Epidemiol 2017;31:338-45. doi:10.1111/ppe.12368

6 Iliodromiti S, Mackay DF, Smith GCS, Pell JP, Nelson SM. Apgar score and the risk of cause-specific infant mortality: a population-based cohort study. Lancet 2014;384:1749-55. doi:10.1016/S01406736(14)61135-1
7 Casey BM, McIntire DD, Leveno KJ. The continuing value of the Apgar score for the assessment of newborn infants. N Engl / Med 2001:344:467-71. doi:10.1056/NEIM200102153440701

8 Cnattingius S, Norman M, Granath F, Petersson G, Stephansson O, Frisell T. Apgar score components at 5 minutes: risks and prediction of neonatal mortality. Paediatr Perinat Epidemiol 2017;31:328-37. doi:10.1111/ppe.12360

9 Thorngren-Jerneck K, Herbst A. Low 5-minute Apgar score: a population-based register study of 1 million term births. Obstet Gynecol 2001;98:65-70

10 Salustiano EMA, Campos JADB, Ibidi SM, Ruano R, Zugaib M. Low Apgar scores at 5 minutes in a low risk population: maternal and obstetrical factors and postnatal outcome. RevAssoc Med Bras (1992) 2012;58:587-93. doi:10.1590/S010442302012000500017

11 Moore EA, Harris F, Laurens KR, et al. Birth outcomes and academic achievement in childhood: A population record linkage study. J Early Child Res 2014;12:234-50. doi:10.1177/1476718X13515425.

12 Odd DE, Rasmussen F, Gunnell D, Lewis G, Whitelaw A. A cohort study of low Apgar scores and cognitive outcomes. Arch Dis Child Fetal Neonatal Ed 2008;93:F115-20. doi:10.1136/adc.2007.123745

13 Ehrenstein V, Pedersen L, Grijota M, Nielsen GL, Rothman KJ. Sørensen HT. Association of Apgar score at five minutes with longterm neurologic disability and cognitive function in a prevalence study of Danish conscripts. BMC Pregnancy Childbirth 2009;9:14. doi:10.1186/1471-2393-9-14

14 Moster D, Lie RT, Markestad T. Joint association of Apgar scores and early neonatal symptoms with minor disabilities at school age. Arch Dis Child Fetal Neonatal Ed 2002;86:F16-21. doi:10.1136/ fn.86.1.F16

15 Marschik PB, Einspieler C, Garzarolli B, Prechtl HF. Events at early development: are they associated with early word production and neurodevelopmental abilities at the preschool age?Early Hum Dev 2007;83:107-14. doi:10.1016/j.earlhumdev.2006.05.009

16 Krebs L, Langhoff-Roos J, Thorngren-Jerneck K. Long-term outcome in term breech infants with low Apgar score--a population-based followup. Eur J Obstet Gynecol Reprod Biol 2001;100:5-8. doi:10.1016/ S0301-2115(01)00456-0

17 Swedish National Board of Health and Welfare. The Swedish Medical Birth Register: a summary of content and quality. 2003.

18 Swedish National Board of Health and Welfare. The National Board of Health and Welfare. The Swedish Medical Birth Register. A summary of content and quality. 2014

19 Ludvigsson JF, Andersson E, Ekbom A, et al. External review and validation of the Swedish national inpatient register. BMC Public Health 2011;11:450. doi:10.1186/1471-2458-11-450

20 Swedish National Board of Health and Welfare. Quality and content in the Swedish Patient Register. 2013.

21 Swedish National Board of Health and Welfare. Causes of death. 2013.

22 Statistics Sweden. Evaluation of the Swedish register of education. 2006.

23 Ludvigsson JF, Almqvist C, Bonamy AK, et al. Registers of the Swedish total population and their use in medical research. Eur J Epidemiol 2016;31:125-36. doi:10.1007/s10654-016-0117-y

24 World Health Organization. Global Database on Body Mass Index: BMI Classification.

25 Lai S, Flatley C, Kumar S. Perinatal risk factors for low and moderate five-minute Apgar scores at term. Eur J Obstet Gynecol Reprod Biol 2017:210:251-6. doi:10.1016/j.ejogrb.2017.01.008

26 O'Donnell CP, Kamlin COF, Davis PG, Carlin JB, Morley CJ. Interobserver variability of the 5-minute Apgar score. J Pediatr 2006;149:486-9. doi:10.1016/j.jpeds.2006.05.040

27 Lopriore E, van Burk GF, Walther FJ, de Beaufort AJ. Correct use of the Apgar score for resuscitated and intubated newborn babies: questionnaire study. BM/ 2004:329:143-4. doi:10.1136/ bmj.38117.665197.F7

28 Bergamasco B, Benna P, Ferrero P, Gavinelli R. Neonatal hypoxia and epileptic risk: a clinical prospective study. Epilepsia 1984;25:131-6. doi:10.1111/j.1528-1157.1984.tb04168.x

29 Sabol BA, Caughey AB. Acidemia in neonates with a 5-minute Apgar score of 7 or greater - What are the outcomes?Am J Obstet Gynecol 2016:215:486 doi:10.1016/i.ajog 2016.05.035

30 Modabbernia A, Sandin S, Gross R, et al. Apgar score and risk of autism. Eur J Epidemiol 2019;34:105-14. doi:10.1007/s10654018-0445-1

31 American Academy of PediatricsCommittee on Fetus and NewbornAmerican College of Obstetricians and GynecologistsCommittee on Obstetric Practice. The Apgar score. Adv Neonatal Care 2006;6:220-3. doi:10.1016/j.adnc.2006.04.008

Supplementary materials: Supplementary tables A-D 